\title{
Anopheles aquasalis Eggs from Two Venezuelan Localities Compared by Scanning Electron Microscopy
}

\author{
V Maldonado, HJ Finol*, JC Navarro ${ }^{+}$ \\ Instituto de Zoología Tropical, Laboratorio de Biología de Vectores, Facultad de Ciencias, Universidad Central \\ de Venezuela, Apartado 47058, Caracas 1041-A, Venezuela *Centro de Microscopía Electrónica, Facultad de \\ Ciencias, Universidad Central de Venezuela, Apartado 47114, Caracas 1041-A, Venezuela
}

Anopheles (Nyssorhynchus) aquasalis, is the main coastal vector of malaria from northeastern Venezuela to southeastern Brazil. Several authors have argued that An. aquasalis is a highly polymorphic species while others indicated that it is a complex of closely related species. This investigation compared the morphology of An. aquasalis eggs from Sinamaica (Zulia State) and Yaguaraparo (Sucre State), the west and east of Venezuela, respectively. We were able to separate eggs from the two localities using discriminant analyses based on ratios and percentages of anterior and posterior tubercles measured by scanning electron microscopy. The results of this work suggest that An. aquasalis has high intraspecific variation.

Key words: Anopheles aquasalis - scanning electron microscopy - eggs - Venezuela

\begin{abstract}
Anopheles (Nyssorhynchus) aquasalis Curry is the main coastal vector of malaria from eastern Venezuela to southern Brazil (Berti et al. 1993). Its coastal distribution ranges from Nicaragua to southern Brazil, Ecuador (although there are no collection records from this country in the Smithsonian's collection), Trinidad and Tobago and the Lesser Antilles (Knight \& Stone 1977, Faran \& Linthicum 1981, Zimmerman 1992). Taxonomically, this species belongs to the Oswaldoi Series in the Albimanus Section of Anopheles, subgenus Nyssorhynchus (Faran 1980, Faran \& Linthicum 1981, Harbach 1994).
\end{abstract}

Given the latitudinal range of An. aquasalis, one might expect that different populations exist with morphological and behavioral variations according to local conditions. The following are variants described as species related to An. aquasalis: An. emilianus Komp, An. guarujaensis Ramos, An. guarauno Anduze, An. delta Anduze (Knight \& Stone 1977), and An. deltaorinoquensis CovaGarcia, which are now regarded as synonyms (Faran 1980).

An. aquasalis has been examined for polymorphisms in proteins (Steiner et al. 1981, Vele 1993,

This study was supported by CDCH 03.023.95 and Conicit RP-VII-240060 to J.C. Navarro

${ }^{+}$Corresponding author. Fax:+58-2-605.2204.

E-mail: jnavarro@ strix.ciens.ucv.ve// jnavarro@neblina.reacciun.ve

Received 12 April 1996

Accepted 4 April 1997
Rangel et al. 1995), polytene chromosomes (Kitzmiller \& Chow 1971, Moncada \& Conn 1992), mitochondrial and ribosomal DNA (Conn et al. 1993) and external morphology (Cova-Garcia 1964, Faran 1980, Gabaldón \& Escalante 1986, Linley et al. 1993b). Some authors suggested that An. aquasalis is a single entity, although Steiner et al. (1982) and Conn et al. (1993) suggested that An. aquasalis could represent a complex of species.

Cova-Garcia (1964) and Gabaldón and Escalante (1986) reported differences in egg morphology with light microscopy, and Moncada and Conn (1992) and Conn et al. (1993) recommended that the morphology of the eggs should be investigated by means of scanning electron microscopy (SEM) to determine the intraspecific variation in An. aquasalis. Accordingly, Linley et al. (1993b) described the eggs of An. aquasalis in populations from Brazil (Rio de Janeiro), Suriname (Paramaribo) and Venezuela (Moron and Caño Rico), representing the first SEM description of egg morphology of An. aquasalis. The objectives of the current investigation were twofold: (1) to provide comparative SEM descriptions of An. aquasalis eggs from two additional localities in Venezuela, Sinamaica, Zulia State (nonvector population) and Yaguaraparo, Sucre State (vector population), in the northwest and northeast, respectively; (2) to conduct statistical analyses of chorionic measurements in order to determine egg differences between the two populations, thus contributing more information about egg morphology of An. aquasalis in Venezuela. 


\section{MATERIALS AND METHODS}

Sources of specimens - Blood fed females of An. aquasalis were collected from animal bait in two localities of Venezuela during the dry season: Sinamaica (SI), Zulia State, 11 ${ }^{\circ} 04^{\prime} 27^{\prime \prime} \mathrm{N}$ 71 ${ }^{\circ} 52^{\prime} 17^{\prime \prime} \mathrm{W}$ and Yaguaraparo (YA), Sucre State, $10^{\circ} 34^{\prime} 27^{\prime}$ 'N 62 49'37'W. Females were identified to species with the keys of Cova-Garcia and Sutil (1977) and Faran (1980).

Females were transferred individually to glass vials containing damp filter paper at the bottom to maintain a high relative humidity. Vials were covered with tulle, fixed with rubber bands and transported to the laboratory in a humidified cooler. Females were kept at $80 \%$ rh, $25-27^{\circ} \mathrm{C}$ until they laid their eggs.

Preparation for scanning electron microscopy - Eggs of 44 females from each locality were given $24 \mathrm{hr}$ to embryonate after oviposition. Those from Zulia State were air-dried and individually placed in the required position on double-faced adhesive tape adhered to stubs, using an extra fine brush (000). Silver tincture was placed on the edges of the adhesive tape in order to ensure electric and thermal conductivity; and the samples were covered with platinum-palladium in an Eico Engineering Model 1B.2 sputter coater. The samples were observed using a Philips Model XL-20 scanning electron microscope operated between 10 and 15 $\mathrm{kV}$. Two permanent records were kept: an image on the hard disc system and photographic records. Eggs from Sucre State were transported in small vials and fixed $24 \mathrm{hr}$ after oviposition in alcoholic Bouin's (ethyl alcohol 80\%, $150 \mathrm{ml}$; concentrated formalin, $60 \mathrm{ml}$; glacial acetic acid, $15 \mathrm{ml}$ and picric acid crystals, $1 \mathrm{~g}$ ). Complete dehydration was initiated with $80 \%$ ethanol using two changes (10 min each) to remove picric acid and increasing the ethanol concentration by $5 \%$ to $100 \%$ (10 min each). Subsequently, the samples were placed on stubs and coated as above.

Data collection and analyses - Length and width of eggs (ventral view), width of the deck at the anterior and posterior ends, and length of the floats and ribs on each float were measured from eggs ( $n=22$ for each locality and female, at random) which were placed on slides in Canada balsam and phenol to maintain their shape. After hardening of the mounting medium, samples were covered with Hoyer's medium and observed under a Wild Model M11 light microscope equipped with an ocular micrometer.

Unstandardized values of all variables were taken into consideration since these attributes possess different dimensions (areas, ratios, and percentages). Evidence from previous studies on mosquitoes (Steinwascher 1984) indicated that the size of eggs may partially depend on the size of the female, which at the same time is influenced by the conditions during larval development (food supply, crowding, temperature). To avoid such influences, we used derived characters (percentages and ratios) in the discriminant analysis (Linley et al. 1993a).

Nine different attributes of the deck tubercles were studied (eggs $=13$ for each locality and female, at random) and five characters of the micropylar apparatus (eggs=9 for each locality and female, at random). Micrographs taken and attributes studied were similar to those previously made by Linley et al. (1993b) for eggs of An. aquasalis. SEM measurements were taken from digital images (stored on the hard disc) using the Philips Analysis Program 2.02.007.

Discriminant analyses were carried out to investigate differences between the SI and YA populations with Statgraphics Plus Version 6.1 Software (Statistical Graphics Corporation, Rockville, MD). The descriptive morphological terminology is based on Harbach and Knight (1980).

\section{RESULTS}

The general description of the eggs of $A n$. aquasalis coincides with that indicated by Linley et al. (1993b); thus, emphasis is placed on the comparison between these two populations.

Comparisons of the measures between SI and YA populations - The mean size of eggs (length and width) was larger in YA than SI. Floats in YA occupied on average $82 \%$ of the length of the egg, while in SI they covered only $70.8 \%$. Anterior tubercles were larger than middle and posterior tubercles (Table I), and were surrounded by smaller, more abundant tubercles (less than $1 \mu \mathrm{m}^{2}$ ) (Fig. 1). Anterior tubercles from SI (Fig. 1a, b) were smaller than those from YA (Fig. 1c, d) (Table I). Middle tubercles were rounder as indicated by larger form factors (Table I). Posterior tubercles were irregular with few, surrounding smaller tubercles, some of which were connected to "large" tubercles by means of bridges (Fig. 2a, b). Middle and posterior tubercles from YA were larger than those from SI, and tubercle density had higher in eggs from SI than those from YA (Table I).

Discriminant analysis - The discriminant analysis of data on tubercles indicated that the anterior and posterior tubercles were the more important variables and provided excellent differentiation of the eggs from both localities. Summary of the discriminant analyses is indicated in Table II. The variants measured in the micropylar apparatus and the anterior/posterior deck width ratio and float attributes did not provide any significant differentiation of eggs from the two localities using discriminant analysis. 
TABLE I

Attributes of the eggs of two populations of Anopheles aquasalis in Venezuela

\begin{tabular}{|c|c|c|}
\hline \multirow[b]{2}{*}{ Attribute } & \multicolumn{2}{|c|}{ Mean $( \pm S D)$ for population } \\
\hline & Yaguaraparo & Sinamaica \\
\hline \multicolumn{3}{|l|}{ Linear dimensions $(\mathrm{n}=22)^{a}$} \\
\hline Egg length & $434.91 \pm 31.86$ & $403.64 \pm 30.48$ \\
\hline Egg width & $218.61 \pm 26.03$ & $182.46 \pm 28.70$ \\
\hline Lenght/width ratio & $2.01 \pm 0.20$ & $2.28 \pm 0.48$ \\
\hline Anterior/posterior deck width ratio & $1.26 \pm 0.5$ & $1.35 \pm 0.21$ \\
\hline \multicolumn{3}{|l|}{ Floats } \\
\hline Mean float length (of the two floats) & $356.07 \pm 28.80$ & $284.24 \pm 28.51$ \\
\hline Mean float length as \% egg length & $82.04 \pm 6.01$ & $70.81 \pm 8.50$ \\
\hline Mean number of ribs (of the two floats) & $29.41 \pm 4.60$ & $21.41 \pm 2.44$ \\
\hline Mean float length/mean number of ribs & $12.36 \pm 2.00$ & $13.39 \pm 1.59$ \\
\hline \multicolumn{3}{|l|}{ Tubercles $(n=13)$} \\
\hline Anterior deck tubercle density ${ }^{b}$ & $65.16 \pm 19.10$ & $92.12 \pm 17.62$ \\
\hline Mean anterior deck tubercle area ${ }^{c}$ & $1.48 \pm 0.53$ & $1.12 \pm 0.22$ \\
\hline Mean anterior deck tubercle form factor ${ }^{d}$ & $0.53 \pm 0.10$ & $0.56 \pm 0.09$ \\
\hline Middle deck tubercle density & $81.96 \pm 13.44$ & $109.40 \pm 18.53$ \\
\hline Mean middle deck tubercle area & $1.04 \pm 0.33$ & $0.65 \pm 0.08$ \\
\hline Mean middle deck tubercle form factor & $0.59 \pm 0.22$ & $0.58 \pm 0.07$ \\
\hline Posterior deck tubercle density & $82.77 \pm 25.54$ & $93.12 \pm 21.08$ \\
\hline Mean posterior deck tubercle area & $1.11 \pm 0.39$ & $0.78 \pm 0.20$ \\
\hline Mean posterior deck tubercle form factor & $0.50 \pm 0.13$ & $0.55 \pm 0.11$ \\
\hline \multicolumn{3}{|l|}{ Micropyle $(n=9)$} \\
\hline Total area of micropylar apparatus & $404.01 \pm 78.40$ & $409.66 \pm 75.69$ \\
\hline Collar area of micropylar apparatus & $263.08 \pm 51.43$ & $265.42 \pm 50.55$ \\
\hline Disk area of micropylar apparatus & $140.93 \pm 30.90$ & $144.46 \pm 32.00$ \\
\hline Disk area as \% total apparatus area & $34.83 \pm 2.93$ & $35.23 \pm 4.25$ \\
\hline Number of sectors in micropylar disk & $6.56 \pm 0.73$ & $6.44 \pm 0.73$ \\
\hline Diameter micropyle & $2.79 \pm 0.63$ & $3.26 \pm 0.47$ \\
\hline
\end{tabular}

$a$ : all linear measurements in $\mu \mathrm{m} ; b$ : number in an area of $400 \mu \mathrm{m}^{2} ; c$ : all area measurements in $\mu \mathrm{m}^{2} ; d$ : form factor $=4 \mathrm{x} \pi \mathrm{x}$ area/perimeter ${ }^{2}$ (index of roundness); SD: standard deviation
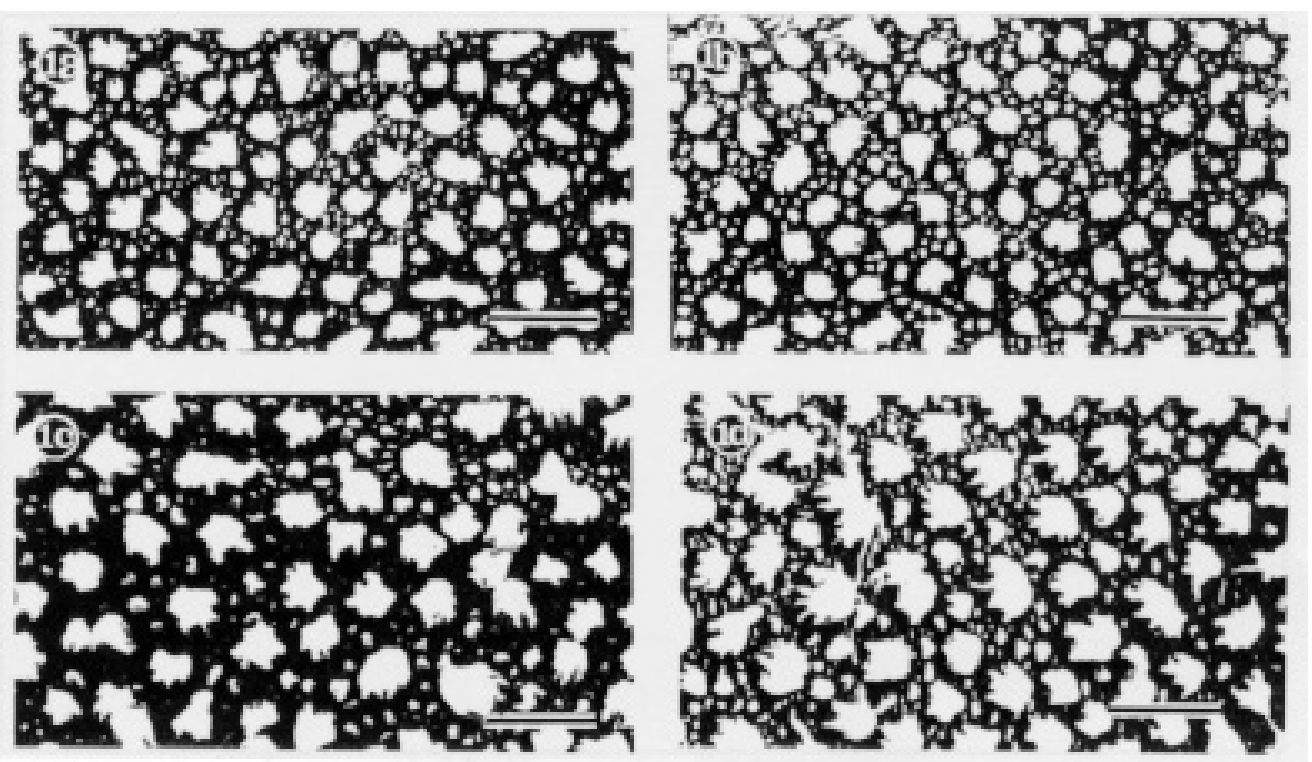

Tubercles, anterior deck, different females. Fig. 1a, b: Sinamaica. Fig. 1c, d: Yaguaraparo. Bar $=10 \mu \mathrm{m}$. 

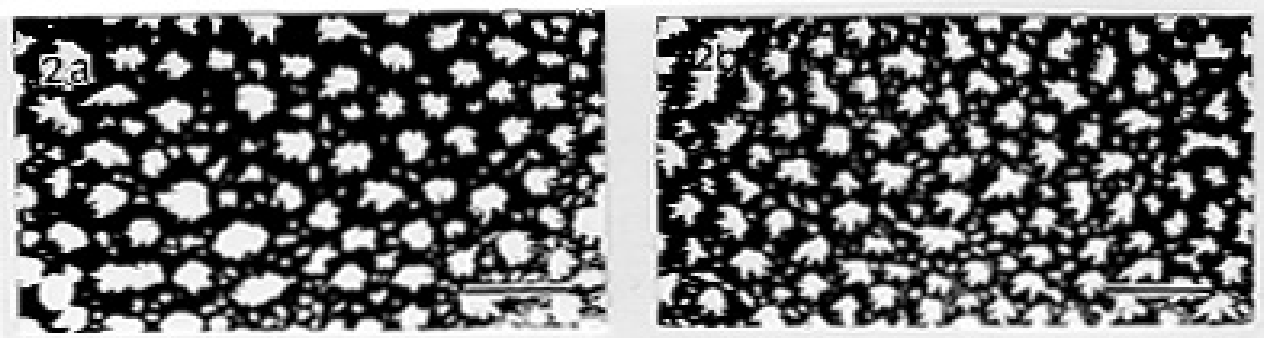

Tubercles, posterior deck. Fig. 2a: Sinamaica. Fig. 2b: Yaguaraparo. Bar $=10 \mu \mathrm{m}$.

TABLE II

Summary of discriminant analysis

\begin{tabular}{lcccr}
\hline Discriminant analysis & Eigenvalues & Chi-square & df & p \\
\hline $\begin{array}{l}\text { Micropylar apparatus } \\
\begin{array}{l}\text { Ratio and percentages measured } \\
\text { by optical microscopy }\end{array}\end{array}$ & 0.3848038 & 4.2322601 & 6 & 0.64528 \\
\begin{tabular}{l} 
Tubercles \\
\hline
\end{tabular} & 6.8521945 & 24.654846 & 4 & 0.67831 \\
\hline
\end{tabular}

df: degree of freedom; p: probability

\section{DISCUSSION}

The discriminant analysis differentiated the two localities studied, supporting the idea of intraspecific variation, as observed by Steiner et al. (1981), Moncada and Conn (1992) and Rangel et al. (1995). Linley et al. (1993b) described the eggs of An. aquasalis from Venezuela (CR and MO) as having shorter floats, larger decks not tapered posteriorly, and a greater width in relation to egg length. Also, the tubercles of the anterior deck seen under high magnification differentiated populations. Our results agree with these observations. Attributes that contributed more to differentiation included the anterior and posterior tubercles, with the anterior tubercles contributing more to the differentiation of the two analyzed populations.

The populations of An. aquasalis analyzed here (SI and YA) and by Linley et al. (1993b) (MO and CR) (Fig. 3) span the Venezuelan coast from east to west. Intraspecific differences among the four populations are basically in the length and width of the egg, the floats, and anterior tubercles. This characteristics could be suggested as diagnostic markers in eggs taxonomy of An. aquasalis by SEM. However, these characters did not show evidence of morphological sharp discontinuities between Venezuelan samples of malaria vectors (YA) and nonvectors (MO, CR and SI) populations. This results and the more or less continuous coastal habitat of An. aquasalis and the apparent geographical continuity of the Venezuelan coast, (with no im-

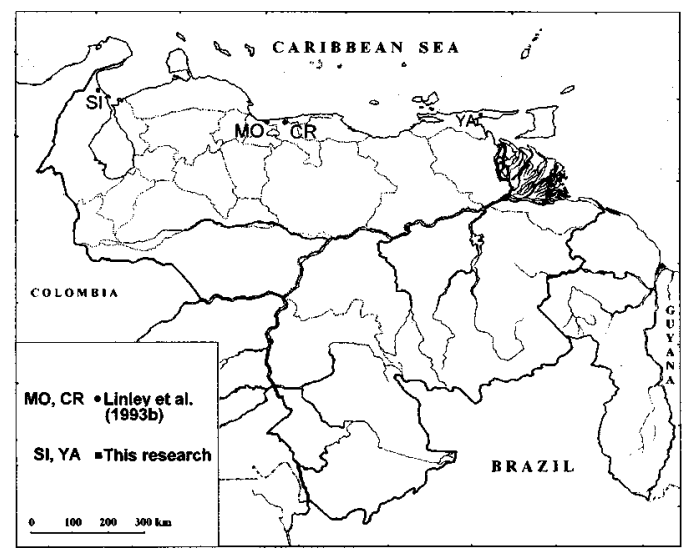

Fig. 3: map of Venezuela showing location of Anopheles aquasalis populations analyzed by scanning electron microscopy.

portant geographical barriers since the MioPliocene), provides biogeographical support to the hypothesis that in Venezuela An. aquasalis is a species with high intraspecific variation. The same could be said about An. aquasalis from Trinidad, which is a continental island sharing the same geological origin as the Venezuelan Cordillera de la Costa (coastal range). From its close proximity and recent isolation (change of sea level in the latest glaciation) one would not expect to find any major differences in the coastal Venezuelan and Trinidad 
populations of An. aquasalis, such as those reported by Conn et al. (1993) among Venezuelan (MO, SF)/ Trinidadian (PS) and Brazilian (MJ, RJ) populations.

Also, our results and the reports of Conn et al. (1993) and Moncada and Conn (1992) on Sucre State populations (YA, Santa Fe and Guayana) compared with west and central populations (SI, MO, CR and Puerto Cabello) might suggest that Cova-Garcia's interpretation of the egg morphology (An. emilianus) was mistaken.

This investigation supports the hypothesis of intraspecific variation in An. aquasalis and demonstrates the usefulness of studying the morphology of anopheline eggs with SEM. Similar studies should be done throughout the range of the species to determine the continuity of structural variants and confirm the existence of morphological differences that would allow the characterization of different populations, including vector competence studies. It is recommended that future analyses take into consideration the effects of seasonal variation (wet and dry seasons) and different habitats (eggs from fresh and brackish water populations) on egg morphology. Finally, polymorphism in proteins and mitocondrial and ribosomal DNA studies must be done including SI, YA populations and compare with the anothers Venezuelan and Sudamerican localities.

\section{ACKNOWLEDGMENTS}

To inspectors Humberto Montañez and Jesus Amarista for field assistance. To Centro de Microscopía Electrónica, Facultad de Agronomía, UCV, (CeMEFA), and Centro de Microscopía Electrónica, Facultad de Ciencias, UCV. To Hermes Piñango (Laboratorio de Biología de Vectores) and Carlos Chedas (CeMEFA) for valuable contribution. To Dr Alan Wheeler (University of Keele, U.K.) for final translate revision.

\section{REFERENCES}

Berti J, Zimmerman RH, Amarista J 1993. Spatial and temporal distribution of Anopheline larvae in two malarious areas in Sucre State, Venezuela. Mem Inst Oswaldo Cruz 88: 353-362.

Conn J, Cockburn AF, Mitchell SE 1993. Population differentiation of the malaria vector Anopheles aquasalis using mitochondrial DNA. J Hered 84: 248-253.

Cova-Garcia P 1964. Sobre Anopheles Nyssorhynchus emilianus Komp, 1941. Rev Venez Sanid Asist Soc 24: 199-217.

Cova-Garcia P, Sutil O 1977. Claves gráficas para la clasificación de anofelinos de Venezuela. Publ. Div. Endem. Rurales Dir. Malariol. Saneam. Minist. Sanid. Asist. Soc. 92 pp.

Faran ME 1980. Mosquito studies (Diptera: Culicidae).
XXXIV. A revision of the Albimanus section of the subgenus Nyssorhynchus of Anopheles. Contrib Am Entomol Inst 15: 1-215.

Faran ME, Linthicum KJ 1981. A handbook of the Amazonian species of Anopheles (Nyssorhynchus) (Diptera: Culicidae). Mosq Syst 13: 1-81.

Gabaldón A, Escalante C 1986. Estudio de los huevos de Anopheles emilianus en tres regiones de Venezuela. Dir. Malariol. Saneam. Ambient. Maracay. Mimeographed Document. 8 pp.

Harbach RE 1994. Review of the internal classification of the genus Anopheles (Diptera: Culicidae): The foundation for comparative systematics and phylogenetic research. Bull Entomol Res 84: 331-342.

Harbach RE, Knight KL 1980. Taxonomists' glossary of mosquitos anatomy. Plexus Publishing, Inc., Marlton, New Jersey, 413 pp.

Kitzmiller JB, Chow GW 1971. The salivary gland chromosomes of An. aquasalis. Rev Bras Malariol Doencas Trop 23: 65.

Knight K, Stone A 1977. A catalog of the mosquitoes of the world. Thomas Say Foundation, Vol. VI. 2nd. ed. Entomol. Soc. Amer, 611 pp.

Linley JR, Kaiser PE, Cockburn AF 1993a. A description and morphometric study of the eggs of species of the Anopheles quadrimaculatus complex (Diptera: Culicidae). Mosq Syst 25: 124-147.

Linley JR, Lounibos LP, Conn J 1993b. A description and morphometric analysis of the eggs of four South American populations of Anopheles (Nyssorhynchus) aquasalis (Diptera: Culicidae). Mosq Syst 25: 198214.

Moncada A, Conn J 1992. A polytene chromosome study of four populations of Anopheles aquasalis from Venezuela. Genome 35:327-331

Rangel Y, Vele G, Chadee DD 1995. Population genetic analysis of Anopheles aquasalis in Venezuela and Trinidad. J Am Mosq Control Assoc 11: 347.

Steiner WWM, Kitzmiller JB, Osterbur DL 1981. On the genetic identity and evolution of the malaria vectors Anopheles aquasalis Curry and Anopheles emilianus Komp, p. 75-90. In R Pai, JB Kitzmiller, $\mathrm{T}$ Kanda (eds) Cytogenetics and genetics of vectors. Elseiver, Amsterdam.

Steiner WWM, Narang S, Kitzmiller JB, Swofford DL 1982. Genetic divergence and evolution in Neotropical Anopheles (Subgenus Nyssorhynchus), p 523550. In WWM Steiner, KS Tabachnik, KS Rai, S Narang (eds) Recent developments in the genetics of insect disease vectors. Champaign, Illinois.

Steinwascher K 1984. Eggs size variation in Aedes aegypti: relationship to body size and other variables. Am Midl Nat 112: 76-84.

Vele G 1993. Estructura genética de poblaciones de Anopheles (Nyssorhynchus) aquasalis Curry 1932 (Diptera: Culicidae). Trabajo Especial de Grado. Universidad Central de Venezuela, Caracas, 60 pp.

Zimmerman RH 1992. Ecology of malaria vectors in the Americas and future direction. Mem Inst Oswaldo Cruz 87: 371-383. 
492 A. aquasalis Eggs Compared in Venezuela by SEM • V Maldonado et al. 